\title{
Visible-light Responsive Cu-MOF-NH 2 for Highly Efficient Aerobic Photocatalytic Oxidation of Benzyl Alcohol
}

\section{Samira Abdel-Azim}

Egyptian Petroleum Research Institute (EPRI)

Delvin Aman ( $\square$ delvin.aman@epri.sci.eg)

Egyptian Petroleum Research Institute (EPRI)

eric van steen

Univerity of Cape Town

Howaida Abd El Salam

Egyptian Petroleum Research Institute (EPRI)

\section{Research Article}

Keywords: Benzyl alcohol, benzaldehyde, benzyl benzoate, Photocatalysis, Cu-MOF, Cu-MOF-NH2

Posted Date: October 14th, 2021

DOI: https://doi.org/10.21203/rs.3.rs-963756/v1

License: (c) (i) This work is licensed under a Creative Commons Attribution 4.0 International License. Read Full License 


\title{
Visible-light responsive $\mathrm{Cu}-\mathrm{MOF}-\mathrm{NH}_{2}$ for highly efficient aerobic photocatalytic oxidation of benzyl alcohol
}

\author{
Samira Abdel-Azimª , Delvin Aman*b,c, , Eric Van Steen ${ }^{* *}$, Howaida Abd El \\ Salam ${ }^{\mathrm{e}}$ \\ ${ }^{\text {a }}$ Process Development Division, Egyptian Petroleum Research Institute (EPRI), Nasr city, 11727 , \\ Cairo, Egypt. \\ ${ }^{\mathrm{b}}$ Catalysis Laboratory, Refining Department, Egyptian Petroleum Research Institute (EPRI), Nasr city, \\ 11727, Cairo, Egypt \\ ' EPRI-Nanotechnology Center' Egyptian Petroleum Research Institute (EPRI), Nasr City, 11727 , \\ Cairo, Egypt, E-mail: delvin.aman@epri.sci.eg \\ ${ }^{\mathrm{d}}$ Catalysis Institute, Department of Chemical Engineering, Univerity of Cape Town, Private Bag X3, \\ Rondebosch 7701, South Africa, E-mail: eric.vansteen@uct.ac.za. \\ e Analysis and Evaluation Division, Egyptian Petroleum Research Institute (EPRI), Nasr City, 11727, \\ Cairo, Egypt.
}

\begin{abstract}
The current study focuses on the photocatalytic oxidation of benzyl alcohol in acetonitrile under air bubbling conditions comparing titania-based materials, $\mathrm{Cu}-\mathrm{MOF}$, and $\mathrm{Cu}-\mathrm{MOF}-\mathrm{NH}_{2}$ as semiconductor photocatalysts. The catalysts were characterized by XRD, $\mathrm{N}_{2}$ adsorption-desorption, FT-IR, Raman spectroscopy, and TEM. The photocatalytic benzyl alcohol conversion reached $\sim 100 \%$ after exposing the four prepared catalysts to a $125 \mathrm{~W}$ mercury lamp for up to $240 \mathrm{~min}$. Benzaldehyde is formed with a moderate selectivity (after a reaction time of $60 \mathrm{~min}$. ca. $30 \%$ over the titaniabased catalysts 37\%, 45\% over $\mathrm{Cu}-\mathrm{MOF}$, and $\mathrm{Cu}-\mathrm{MOF}-\mathrm{NH}_{2}$, respectively). The formation of electron-hole pairs at the surface of the semiconductor nanoparticles followed by oxidation reaction was the suggested mechanism. A first-order kinetic model was observed for the photocatalytic oxidation of the investigated alcohols, and the rate constants were calculated. According to preliminary research, decorating MOF linker by amine (MOF-NH$)$ could improve visible-light harvesting, charge separation, and electron transport of the resulting catalyst, resulting in increased photocatalytic activity. The current work offers some direction for the development of MOF-based photocatalysts for organic synthesis.
\end{abstract}

Keywords: Benzyl alcohol, benzaldehyde, benzyl benzoate, Photocatalysis, $\mathrm{Cu}-\mathrm{MOF}, \mathrm{Cu}-\mathrm{MOF}-\mathrm{NH}_{2}$ 


\section{Introduction:}

Environmental protection and energy efficiency are currently crucial and pressing issues for the entire world. Hence, more environmentally benign and energy-efficient processes are being developed. Photocatalytic processes using semiconductors can be considered an integral part of environmentally benign processing [1-3]. Selective photocatalytic conversion or partial photocatalysis can potentially be applied to the synthesis of fine chemicals $[4,5]$, such as oxidation of aromatic alcohols to aromatic aldehydes [6,7], which are essential intermediates for the synthesis of numerous valuable chemicals [8]. For instance, the most simple aromatic aldehyde, benzaldehyde [9], is used in various applications ranging from an industrial solvent to commercial food flavoring. Furthermore, benzaldehyde is an intermediate in the synthesis of different perfumes and dyes.

The photocatalytic oxidation of benzyl alcohol reaction has two typical by-products; benzoic acid and benzyl benzoate [10]. The benzoic acid is typically present at low concentration in the reaction medium (near or under detection limit) because benzoic acid may react with unconverted benzyl alcohol, resulting in the formation of benzyl benzoate [10]. Skupien et al. argued that benzyl benzoate is predominantly produced in the oxidative reaction under base conditions via the esterification of benzyl alcohol with benzaldehyde [11].

Titanium dioxide is a well-known photocatalyst, which has excellent potential as a tool in green organic synthesis [12,13], for instance, for the oxidation of benzyl alcohol oxidation to benzaldehyde [14]. The $\mathrm{TiO}_{2}$ properties, particularly their crystalline phase [15], and the mode of adsorption of organic molecules on its surface are the main factors affecting selective photocatalytic activity [16,17]. In most photooxidation applications, anatase, pure or mixed with rutile, has a higher photocatalytic activity than pure rutile and brookite [18]. The activity is attributed to a higher density of localized states and consequent surface-adsorbed hydroxyl radicals and slower charge carrier recombination in anatase relative to rutile [19]. Indeed, the preparation of anatase-rutile mixed-phase $\mathrm{TiO}_{2}$ (anatase and rutile phases in 4:1 ratio) such as commercial $\mathrm{TiO}_{2}$ Degussa P25 exhibits the highest photocatalytic activity due to the synergistic effect between anatase and rutile, resulting in an effective separation of photo-induced 
electrons and holes [20]. Titania adsorb light in the UV range as the bandgap of anatase is $3.2 \mathrm{eV}$ and rutile $3.0 \mathrm{eV}$. Shifting the absorption from UV light to visible light would increase solar light utilization since UV light accounts for only 4\%. As a result, the presence of rutile in an anatase-forming mixture may be responsible for increasing the $\mathrm{TiO}_{2}$ anatase phase towards light absorptivity in the visible range [21].

Metal-organic frameworks (MOFs) are an attractive class of porous crystalline materials consisting of metal ions and poly-functional organic linkers that possess properties, such as high specific surface areas, large pore volumes, and structural flexibility and adaptability. These properties allow MOFs to be used in different applications, including adsorption and separation [22,23], heterogeneous catalysis [2325], drug delivery [26], and sensing [27]. MOFs have recently also been used as photocatalysts due to their tunable properties for light absorption and the capability to incorporate various functional components in a single MOF material [28]. MOFs are regarded as semiconductor-like materials, with the metal cluster as the conduction band and the organic linker as the valence band [29]. Furthermore, for various photocatalytic reactions, the highly crystalline nature of MOFs results in a fast electron and energy transfer from the photoexcited MOFs to the active sites [30]. Cu-MOF was found as a UV-responsive photocatalyst because it is known to act like a wide-band semiconductor [31]. A convenient and viable method for tuning the optical characteristics of MOFs is to decorate the organic linkers or metal centers, therefore controlling the chemical and physical characteristics of photocatalysts at the molecular level. However, the photocatalytic efficiency of pure MOF is limited, so the decoration of linkers or metal centers with semiconductors and/ or metal nanoparticles (NPs) is necessary [24]. The amine group $\left(\mathrm{NH}_{2}\right)$ linker decoration has shown a beneficial photocatalytic activity to selectively oxidize organic compounds [32-34]. The linker decorating may modify the bandgap energy of MOFs to a certain level; for example, stronger electron-donating substitutions such as amines dramatically lower the band gap, shifting the photo absorption edge from the ultraviolet to visible light area [35].

Here, we report on the selective photocatalytic aerobic oxidation of benzyl alcohol using $\mathrm{TiO}_{2}$ (pure anatase), $\mathrm{TiO}_{2}$ (anatase: rutile $=4: 1$ ), $\mathrm{Cu}-\mathrm{MOF}$, and $\mathrm{Cu}-\mathrm{MOF}-\mathrm{NH}_{2}$ catalysts under irradiation with visible light. In particular, we have focused on the mechanisms of the selective photocatalytic oxidation of benzyl alcohol to benzaldehyde and benzyl benzoate. 


\section{Experimental methodology}

\subsection{Material synthesis}

\section{Preparation of nanoparticles $\mathrm{TiO}_{2}$ by sol-gel method}

Titanium dioxide nano-catalysts were prepared by the sol-gel method using titanium tetra-isopropoxide, TTIP (97\% Sigma-Aldrich). The used molar ratio 2:22.5:3 is for TTIP/isopropanol(i-PrOH)/modifier of $\mathrm{pH}$ by adding glacial acetic acid until ( $\mathrm{pH} 3-$ 4.5) or an ammonium hydroxide solution (ACS reagent, $\left.\mathrm{NH}_{3}, 28.0-30.0 \%\right)$ until ( $\mathrm{pH}$ 7-9), respectively. The mixture was sonicated for $1 \mathrm{~h}$, during which time partial hydrolysis and polymerization occurred, producing a transparent, homogeneous, and stable solution. After gelation for $24 \mathrm{~h}$, the final gel material was dried overnight at 110 ${ }^{\circ} \mathrm{C}$ and subsequently calcined at $550{ }^{\circ} \mathrm{C}$ for $4 \mathrm{~h}$ to produce the desired $\mathrm{TiO}_{2}$ photocatalyst. The nomenclature was designed according to the $\mathrm{pH}$ range: $\mathrm{TiO}_{2}(\mathrm{~A})$ in the acidic medium and $\mathrm{TiO}_{2}(\mathrm{~B})$ in the basic medium.

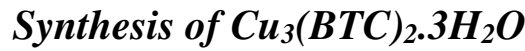

1,3,5-Benzene tricarboxylic acid (BTC, $21 \mathrm{mmol})$ and $\mathrm{Cu}\left(\mathrm{NO}_{3}\right)_{2} \cdot 3 \mathrm{H}_{2} \mathrm{O}(12 \mathrm{mmol})$ were dissolved in a mixture of $125 \mathrm{ml} \mathrm{N}$, N-dimethylformamide (DMF), ethanol $\left(\mathrm{C}_{2} \mathrm{H}_{5} \mathrm{OH}\right)$ and deionized water $(1: 1: 1)$ and sonicated for $15 \mathrm{~min}$ in a $300 \mathrm{ml}$ glass jar. The jar is transferred into the microwave (700 Watt), and the sample was irradiated for $4 \mathrm{~min}$. Blue crystals were formed upon cooling the mixture to room temperature. The product was washed three times with dimethylformamide (DMF) and subsequently with chloroform $\left(\mathrm{CHCl}_{3}\right)$ three times. The product was dried under vacuum at $100{ }^{\circ} \mathrm{C}$ overnight. The produced sample was coded $\mathrm{Cu}-\mathrm{MOF}$.

\section{Functionalization of $\mathrm{Cu}_{3}(\mathrm{BTC})_{2} .3 \mathrm{H}_{2} \mathrm{O}$ by ethylene diamine $(\mathrm{ED})$}

Pristine $\mathrm{Cu}-\mathrm{MOF}$ was dehydrated at $110^{\circ} \mathrm{C}$ for $24 \mathrm{~h}$ before the functionalization. The dehydrated $\mathrm{Cu}-\mathrm{MOF}(0.5 \mathrm{~g})$ was suspended in $30 \mathrm{ml}$ anhydrous toluene. Ethylenediamine $(5 \mathrm{mmol})$ was added to this suspension, after which the suspension was refluxed for $12 \mathrm{~h}$ under continuous stirring [36]. The product was filtered off and 
washed with deionized water. Eventually, the sample then dried at $110{ }^{\circ} \mathrm{C}$ overnight and coded MOF-Cu-NH .

\subsection{Characterization methods}

Powder X-ray diffraction (XRD) analysis carried out with a PAN analytical X'PERT PRO using $\mathrm{Cu}-\mathrm{K} \alpha$ radiation $(\lambda=1.540 \AA)$ to investigate its crystal phase structure and crystalline domain size.

The specific surface area was measured from the $\mathrm{N}_{2}$ adsorption-desorption isotherms at liquid nitrogen temperature $\left(-196^{\circ} \mathrm{C}\right)$ using Quanta-chrome Nova $3200 \mathrm{~S}$ automated gas sorption apparatus. Before such measurements, all samples were degassed overnight at $150^{\circ} \mathrm{C}$ and evacuated $\left(1.3 \times 10^{-3} \mathrm{~Pa}\right)$.

Raman spectra of as-prepared $\mathrm{TiO}_{2}$ (A and B) catalysts were evaluated from 10 to 2000 $\mathrm{cm}^{-1}$ at room temperature using SENTERRA Dispersive Raman Microscope (Bruker) equipped with a diode $\mathrm{Nd}$ : YAG laser at $532 \mathrm{~nm}$ with a maximum laser power of 60 $\mathrm{mW}$ on the sample. A

Fourier-transform infrared spectroscopy (FT-IR) spectrum of the sample was recorded in the transmission mode between $500-4000 \mathrm{~cm}^{-1}$ with an FTIR spectrometer Perkin Elmer (model spectrum one FT-IR spectrometer, USA). Samples were prepared using the standard $1 \% \mathrm{KBr}$ pellets.

High-resolution transmission electron microscopy (HRTEM) was conducted to image the morphology of the surface and structure of the catalysts using JEOL 2010 F, Japan, at an accelerating voltage of $200 \mathrm{kV}$. A small amount of the prepared catalyst was diluted in $10 \mathrm{ml}$ ethanol and sonicated for $30 \mathrm{~min}$. A few drops of the suspension were placed on a covered copper grid and photographed.

The UV-Vis diffuse reflectance spectra (DRS) of the samples over a range of 200-800 nm were recorded by UV-2600 (Shimadzu, Japan) spectrophotometer with $\mathrm{BaSO}_{4}$ as a reference.

\subsection{Photocatalytic conversion reaction of benzyl alcohol}


The catalytic conversion of benzyl alcohol was carried out in a Pyrex cylindrical double-walled immersion well reactor equipped with a 125W mercury lamp (200-420 $\mathrm{nm}$, main wavelength at $365 \mathrm{~nm}$ ) as a light source. Benzyl alcohol was dissolved in acetonitrile (500 mg/L, optimized concentration). Experiments were performed in 150 $\mathrm{ml}$ of the stock solution and catalyst concentration of $1 \mathrm{~g} / \mathrm{L}$ for four hours under the light while bubbling air $(25 \mathrm{~mL} / \mathrm{min})$ through the suspension. The system was cooling by water circulation at $25^{\circ} \mathrm{C}$ during the experiments was performed at constant stirring. The homogenous suspension inside the reactor was vigorously stirred (1100 rpm) at $30^{\circ} \mathrm{C}$. The reaction solution was equilibrated in the dark for $30 \mathrm{~min}$ before each photooxidation reaction. Approx. $3 \mathrm{~mL}$ samples were collected directly from the photoreactor at specific time intervals. The concentrations of the organic product compounds (benzyl alcohol, benzaldehyde, benzoic acid, and benzyl benzoate) were analyzed via GC.

The Conversion (X) and selectivity (S) were determined as follows:

$X(\%)=\left(1-\frac{C_{B A, t}}{C_{B A, 0}}\right) \times 100 \%$

$S(\%)=\frac{C_{B x, t}}{C_{B A, 0}-C_{B A, t}} \times 100 \%$

Where $C_{B A 0}$ is the initial concentration of benzyl alcohol, and $C_{B A}$ and $C_{B x}$ are the concentration of benzyl alcohol and benzaldehyde, benzoic acid, or benzyl benzoate, respectively, at a specific irradiation time of the photocatalytic reaction.

\section{Results and discussion \\ 3.1. Catalysts characterizations}

The XRD patterns of the synthesized titania are shown in Figure 1. The mass fractions of anatase and rutile was evaluated from the reflection of anatase (101) at $2 \theta=25.48^{\circ}$ and the (110) reflection of rutile at $2 \theta=27.58^{\circ}$ can be estimated from [37]:

$$
\chi_{\text {rutile }}=\frac{I_{\text {rutile }}}{I_{\text {rutile }}+0.79 \cdot I_{\text {anatase }}}
$$

where, $\chi_{\text {rutile }}$ is the weight fraction of rutile in the $\mathrm{TiO}_{2}$ and $\mathrm{I}_{\text {rutile, and }} \mathrm{I}_{\text {anatase }}$ are the intensities of the X-ray diffraction lines for rutile and anatase, respectively. On the other 
hand, the size of the crystalline domain of each of the phases is calculated by using Scherrer's equation (4):

$$
D=0.9 \lambda / \beta \cos \theta
$$

Where, $\mathrm{D}$ is the crystallite thickness, $\lambda$ is X-ray wavelength, $\beta$ is FWHM (full width at half max), and $\theta$ is Bragg angle.

The XRD pattern of titania synthesized under acidic conditions $\mathrm{TiO}_{2}(\mathrm{~A})$ consists of 82.6 wt.- $\%$ anatase and 17.4 wt.- $\%$ rutile forms, while XRD pattern for the titania synthesized under basic conditions $\mathrm{TiO}_{2}(\mathrm{~B})$ showed that it was pure anatase. The behavior can be explained by considering the effect of $\mathrm{pH}$ : in a strong acidic medium, rutile dominates over anatase and brookite due to the change of surface properties [38]. In other words, the resistance of anatase transformation to rutile is stronger in basic medium than in acidic medium at the same calcination temperature $\left(550{ }^{\circ} \mathrm{C}\right)$ [39]. The average size of the anatase crystalline domain according to Scherrer's equation in $\mathrm{TiO}_{2}$ (A) $16.8 \mathrm{~nm}$ (using the reflection at $2 \theta=25.48^{\circ}$ ); the average size of the rutile domain was similar $\left(15.2 \mathrm{~nm}\right.$ determined using the reflection at $\left.2 \theta=27.58^{\circ}\right)$. The crystalline domain of anatase in the sample synthesized under basic conditions $\left(\mathrm{TiO}_{2}\right.$ (B)) was slightly smaller (13nm). The difference in the average size of the crystalline domain is related to the growth mechanism: the preparation of $\mathrm{TiO}_{2}$ from (TTIP) included two major steps, viz. hydrolysis, followed by condensation, which is also compatible with the preparation of silica from tetraethoxy [40]. The hydrolysis is acid catalyzed, whereas the condensation reaction seems to base catalyzed. This means that the number of monomers is large under acidic conditions, and at basic conditions, the rate of crystal growth is large. Smaller crystals are more prone to sinter thus resulting after calcination at $550{ }^{\circ} \mathrm{C}$ in a material with larger sizes of the crystalline domains. 


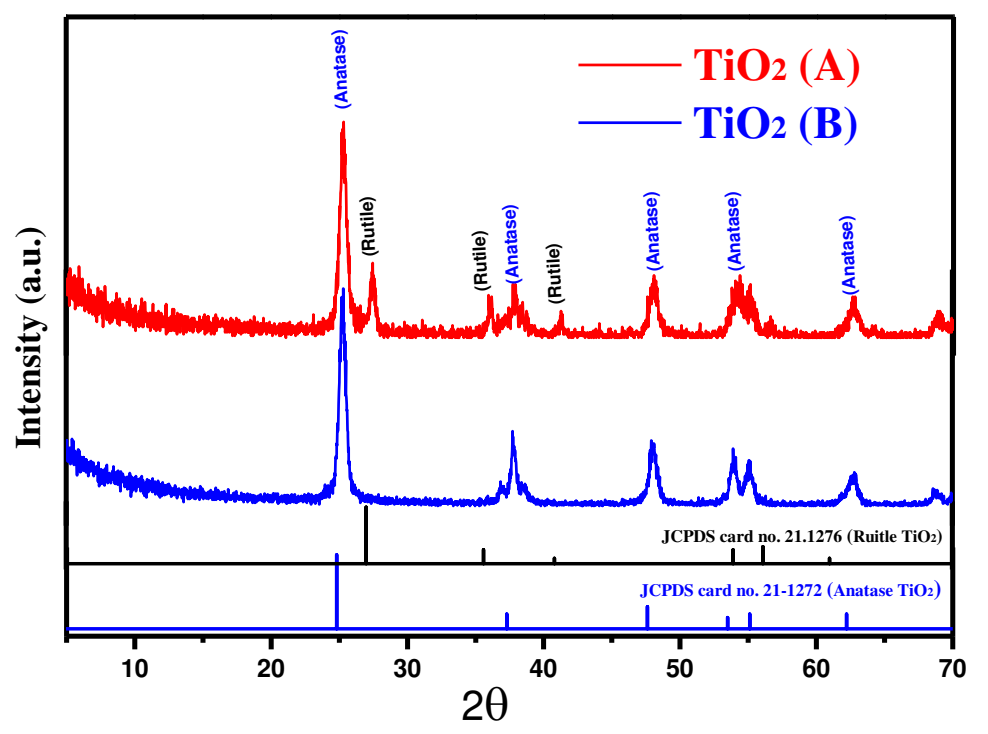

Figure 1: XRD patterns for $\mathrm{TiO}_{2}(\mathrm{~A})$ and $\mathrm{TiO}_{2}(\mathrm{~B})$.

Figure 2 displays the XRD pattern of the simulated, Pristine $\mathrm{Cu}-\mathrm{BTC}$ and $\mathrm{Cu}-\mathrm{MOF}$ $\mathrm{NH}_{2}$. Materials Studio 7.0 software was used to build the XRD pattern for the simulated $\mathrm{Cu}-\mathrm{BTC}$ [41]. Obviously, all the synthesized sample diffraction peaks coincide with the simulated one and imply that the produced $\mathrm{Cu}-\mathrm{BTC}$ is highly purified and crystalline [41]. Additionally, the XRD patterns of the $\mathrm{Cu}-\mathrm{MOF}-\mathrm{NH}_{2}$ sample perfectly resemble the simulated pattern, indicating that the preparation procedure did not alter the framework's topology or texture. However there are some slight variations of the Bragg intensities at $2 \theta=14^{\circ}, 16^{\circ}$ and $40^{\circ}$ were produced by structural damage $[37,41]$.

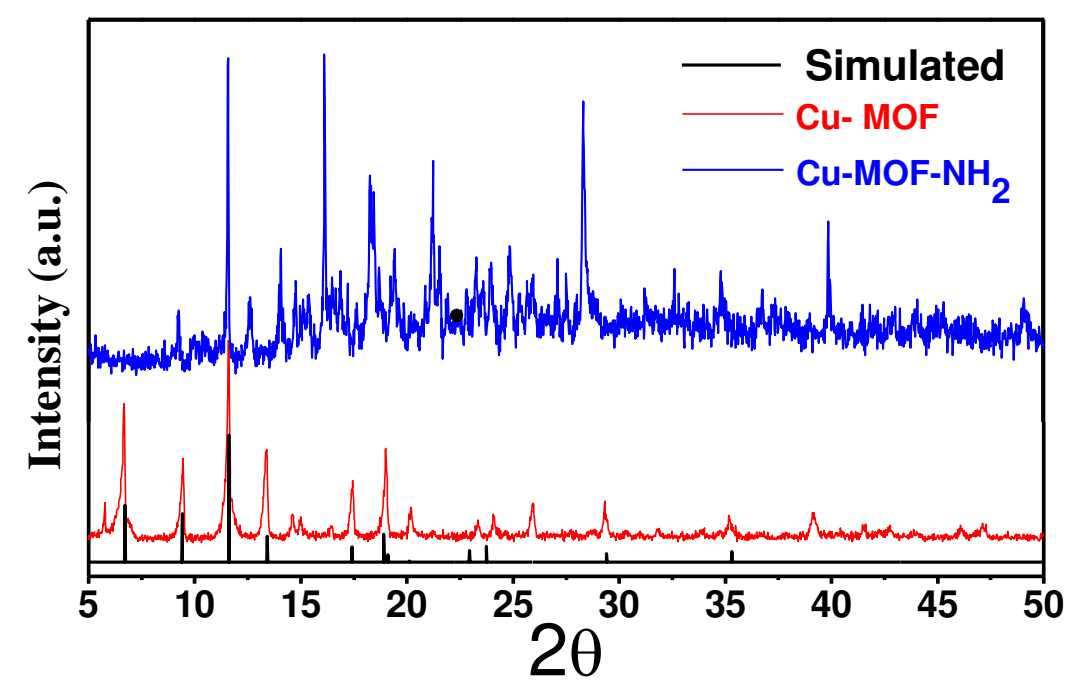

Figure 2: XRD patterns of simulated $\mathrm{Cu}-\mathrm{MOF}$ [41], pristine $\mathrm{Cu}-\mathrm{MOF}$ and (d) $\mathrm{Cu}-\mathrm{MOF}-\mathrm{NH}_{2}$. 
The $\mathrm{N}_{2}$ adsorption/desorption isotherms and pore size distribution were evaluated to characterizing the behavior of the prepared $\mathrm{TiO}_{2}$ catalysts Fig. (S1- S2) and the data present in Table (1). All catalysts show the classical type (IV) isotherm (IUPAC classification). The hysteresis loops of both prepared catalysts are at high relative pressure (0.47-0.93 $\left.P / P^{0}\right)$, thus indicating mesoporous materials [43]. The titania sample prepared under basic conditions, $\mathrm{TiO}_{2}(\mathrm{~B})$, has a higher specific surface area (82 $\left.\mathrm{m}^{2} / \mathrm{g}\right)$ and a higher pore volume $\left(0.17 \mathrm{~cm}^{3} / \mathrm{g}\right)$ than titania prepared under acidic conditions, $\mathrm{TiO}_{2}(\mathrm{~A})\left(\mathrm{S}_{\mathrm{BET}}=65 \mathrm{~m}^{2} / \mathrm{g}\right.$ and $\left.\mathrm{V}_{\text {pore }}=0.13 \mathrm{~cm}^{3} / \mathrm{g}\right)$, which seems to be related to the smaller crystalline domains obtained in $\mathrm{TiO}_{2}(\mathrm{~B})$ compared to $\mathrm{TiO}_{2}(\mathrm{~A})$.

The $\mathrm{N}_{2}$ adsorption/desorption isotherms and pore size distribution of $\mathrm{Cu}-\mathrm{MOF}$ and $\mathrm{Cu}$ MOF- $\mathrm{NH}_{2}$ are shown in Fig. (S3- S4), and the data is present in Table (1). Cu-MOF has a Type (I) isotherm, a feature of microporous substances without a significant contribution of meso and macroporosity. In comparison, the sample $\mathrm{Cu}-\mathrm{MOF}-\mathrm{NH}_{2}$ shows a type(IV) isotherm with mesoporous substances. The BET surface area decreases from 1405 to $54 \mathrm{~m}^{2} / \mathrm{g}$ after $\mathrm{NH}_{2}$ grafting, which indicates that the pores become inaccessible upon modification with ethylenediamine. This is further exemplified by decreasing the total pore volume from $0.95 \mathrm{~cm}^{3} / \mathrm{g} \mathrm{Cu}-\mathrm{MOF}$ to 0.14 $\mathrm{cm}^{3} / \mathrm{g} \mathrm{Cu}-\mathrm{MOF}-\mathrm{NH}_{2}$. That is in agreement with the previously reported data [36].

The Raman spectra of the prepared $\mathrm{TiO}_{2}(\mathrm{~A})$ and $\mathrm{TiO}_{2}$ (B) are shown in (Fig. 2) at the frequency range of $100-1000 \mathrm{~cm}^{-1}$. In $\mathrm{TiO}_{2}(\mathrm{~A})$ catalyst prepared in acidic medium, both peaks at $418.8 \mathrm{~cm}^{-1}$ and $609 \mathrm{~cm}^{-1}$ are observed, corresponding to the $E_{g}$ and $A_{1 g}$ vibrational modes of rutile $\mathrm{TiO}_{2}$. On the other hand, four peaks appearing at $149.1 \mathrm{~cm}^{-1}$ $\left(E_{\mathrm{g}}\right)$ main peak, $398.6 \mathrm{~cm}^{-1}\left(\mathrm{~B}_{1 \mathrm{~g}}\right), 516.2 \mathrm{~cm}^{-1}\left(\mathrm{~A}_{1 \mathrm{~g}}+\mathrm{B}_{1 \mathrm{~g}}\right)$, and $637.3 \mathrm{~cm}^{-1}\left(\mathrm{E}_{\mathrm{g}}\right)$ are observed in $\mathrm{TiO}_{2}(\mathrm{~B})$ samples which correspond to the symmetric modes for anatase phase of $\mathrm{TiO}_{2}$ crystal [44]. This result agrees with the XRD. 


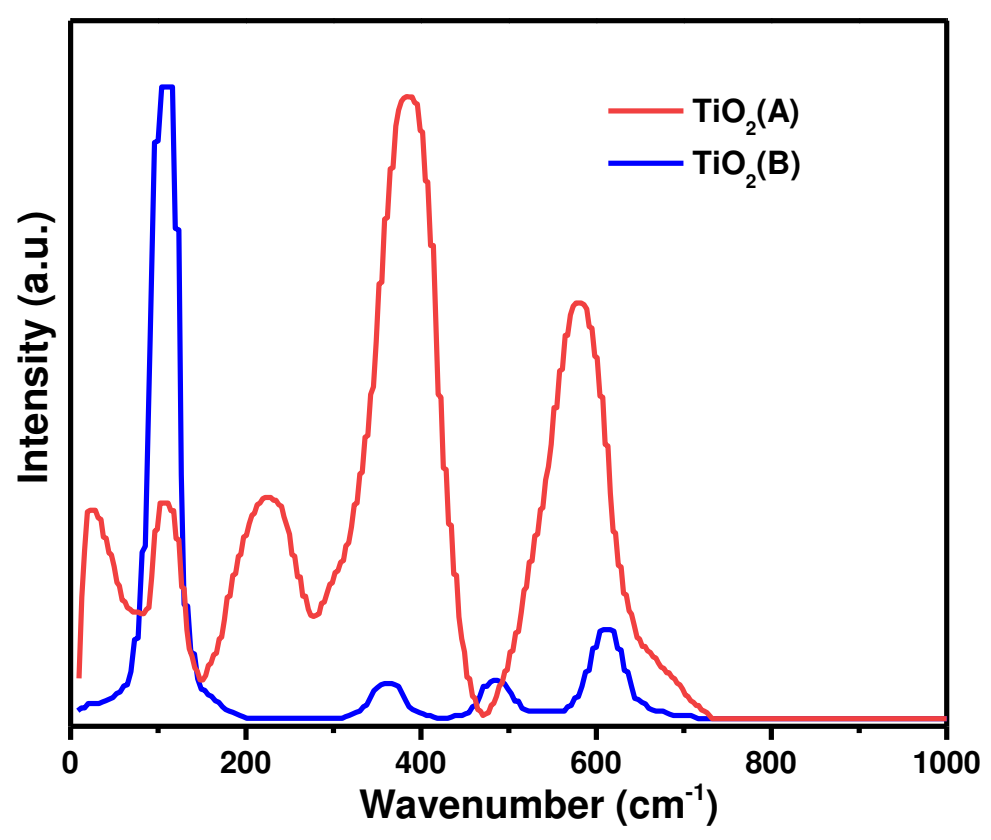

Figure 3: Raman spectra for $\mathrm{TiO}_{2}(\mathrm{~A})$ and $\mathrm{TiO}_{2}(\mathrm{~B})$

The FT-IR experiment was carried out to investigate the intermolecular interactions between ED molecules and MOFs. Figure 4 shows the FT-IR of the pristine Cu-MOF and the $\mathrm{Cu}-\mathrm{MOF}-\mathrm{NH}_{2}$ samples. It is noticed that the spectral band for both samples displays high homogeneity, and the major peaks of both samples resemble well with the published FTIR spectra for Cu-MOF [45]. The FTIR patterns showed absorption bands at 3368 and $2940 \mathrm{~cm}^{-1}$ due to $v(\mathrm{O}-\mathrm{H})$ of the absorbed water and $v\left(\mathrm{CH}_{2}\right)$ vibrations, and absorption at $3500-3000 \mathrm{~cm}^{-1}$ due to $v(\mathrm{OH})$ or $v(\mathrm{NH})$. The vibrational peaks between 2999 and $2850 \mathrm{~cm}^{-1}$ was assigned to the $\mathrm{C}-\mathrm{H}$ stretching vibrations in both materials. However, some variations are noticed, and by comparing with the FTIR of ethylene diamine [46], the spectrum of the $\mathrm{Cu}-\mathrm{MOF}-\mathrm{NH}_{2}$ shows new absorption peaks at 3305 and $3215 \mathrm{~cm}^{-1}$ which can be assigned to the asymmetric and symmetric stretching vibration bond of the $\mathrm{N}-\mathrm{H}[36]$ and at 1033 and $1550 \mathrm{~cm}^{-1}$ which can be attributed to C-N group [47]. 


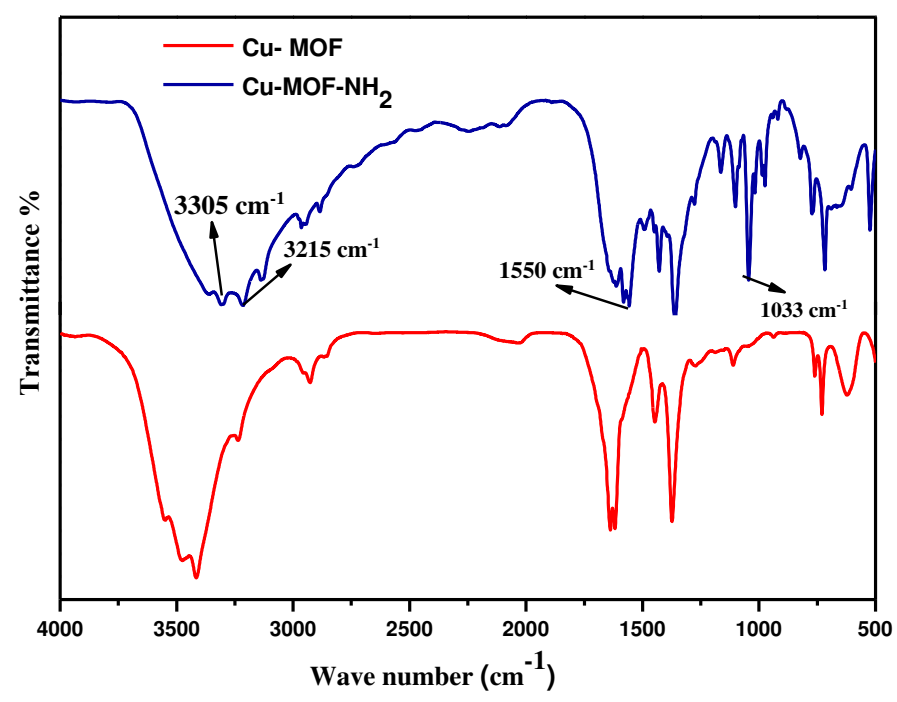

Figure 4: FTIR spectra of pristine $\mathrm{Cu}-\mathrm{MOF}$ and $\mathrm{Cu}-\mathrm{MOF}-\mathrm{NH}_{2}$.

The TEM photographs obtained for the current of both $\mathrm{TiO}_{2}$ samples prepared at acidic and basic mediums are shown in Fig. 5(a and b). It was observed that both samples exhibit particles mainly in the form of rhombohedral and hexagonal prisms with random shapes rather than regular spherical particles. Furthermore, the TEM image of $\mathrm{TiO}_{2}(\mathrm{~A})$ shows the appearance of spotty sharp rings indicative of polycrystalline materials with is for the presence of the rutile phase.

The inset images for the selected area electron diffraction patterns (SAED) of $\mathrm{TiO}_{2}$ prepared, there is the five SAED rings represent anatase phase indexed as (101), (004), (200), (105), and (211) (JCPDS no, 21-1272) in $\mathrm{TiO}_{2}$ (A \& B). Furthermore, in the TiO2 (A) catalyst, the appearance of one ring represents the rutile phase indexed as (110) in addition to five rings of anatase.

Figure 5(c and d ) shows the TEM images of $\mathrm{Cu}-\mathrm{MOF}$ and $\mathrm{Cu}-\mathrm{MOF}-\mathrm{NH}_{2} \cdot \mathrm{Cu}-\mathrm{MOF}$ has a distinct morphology, whilst the morphology of $\mathrm{Cu}-\mathrm{MOF}-\mathrm{NH}_{2}$ seems to be an embedded material with small particles in a matrix. Zhong and his team attributed the morphological change to solvent squeezing during the reflux processes [36]. 

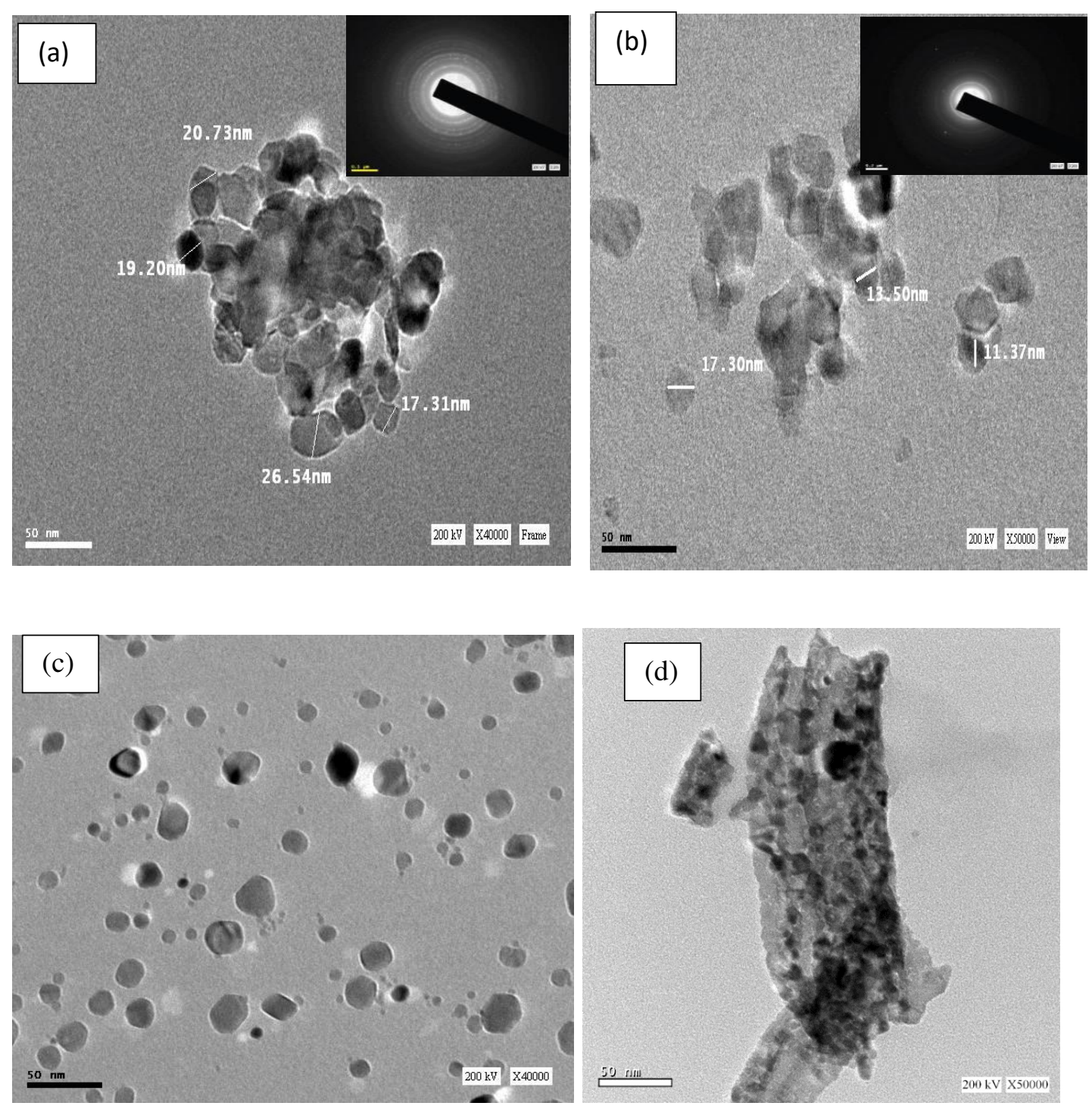

Figure 5: TEM image of (a) $\mathrm{TiO}_{2}(\mathrm{~A})$, (b) $\mathrm{TiO}_{2}(\mathrm{~B})$ inside: selected area electron diffraction patterns (SAED), (c) $\mathrm{Cu}-\mathrm{MOF}$ and (d) $\mathrm{Cu}-\mathrm{MOF}-\mathrm{NH}_{2}$

\subsection{Photocatalytic oxidation of benzyl alcohol}

Before the benzyl alcohol oxidation, the alcohol may adsorb on the surface of the catalysts. The adsorption was investigated with all prepared samples by exposing the catalyst to benzyl alcohol solution in the dark (500 mg benzyl alcohol per gram of solid; see Figure 6 and Table 1). 
Table (1): Average of the crystalline domain, BET-surface area, pore volume and the adsorption capacity properties of the photocatalysts

\begin{tabular}{|c|c|c|c|c|c|}
\hline Sample & $\mathbf{D}_{\text {xrd }}{ }^{[a]} \mathbf{n m}$ & $\begin{array}{l}\mathrm{S}_{B E T}{ }^{[b]} \\
\mathrm{m}^{2} \mathrm{~g}^{-1}\end{array}$ & $\begin{array}{l}V_{p}{ }^{[b]} \\
\mathrm{cm}^{3} \mathrm{~g}^{-1}\end{array}$ & $\begin{array}{l}\text { Adsorption } \\
\text { capacity }^{[c]}, \%\end{array}$ & $\begin{array}{l}\text { Adsorption } \\
\text { capacity/m } / \mathrm{m}^{2} \text { [d] }\end{array}$ \\
\hline $\mathrm{TiO}_{2}(\mathrm{~A})$ & $(16.2 \mathrm{An} \& 15.2 \mathrm{Ru})$ & 65 & 0.13 & 9.9 & 0.15 \\
\hline $\mathrm{TiO}_{2}(\mathrm{~B})$ & 13 An & 82 & 0.17 & 16.3 & 0.20 \\
\hline $\mathrm{Cu}-\mathrm{MOF}$ & 8 & 1405 & 0.95 & 24.6 & 0.02 \\
\hline $\mathrm{Cu}-\mathrm{MOF}-\mathrm{NH}_{2}$ & 14 & 54 & 0.14 & 44.1 & 0.82 \\
\hline
\end{tabular}

[a] Average size of the crystalline domain as determined using the Scherrer equation. (An: anatase and $\mathrm{Ru}$ : rutile phases)

[b] Surface area $\left(\mathrm{S}_{\mathrm{BET}}\right)$ and pore volume $\left(\mathrm{V}_{\mathrm{p}}\right)$ from BET-isotherm.

[c] Fraction of benzyl alcohol adsorbed from a benzyl alcohol solution ([Benzyl alcohol] $=500 \mathrm{mg} / \mathrm{L}$ solid content: $1 \mathrm{~g} / \mathrm{L})$

[d] Adsorption capacity $/ \mathrm{m}^{2}=$ Adsorption capacity $\% /$ surface area

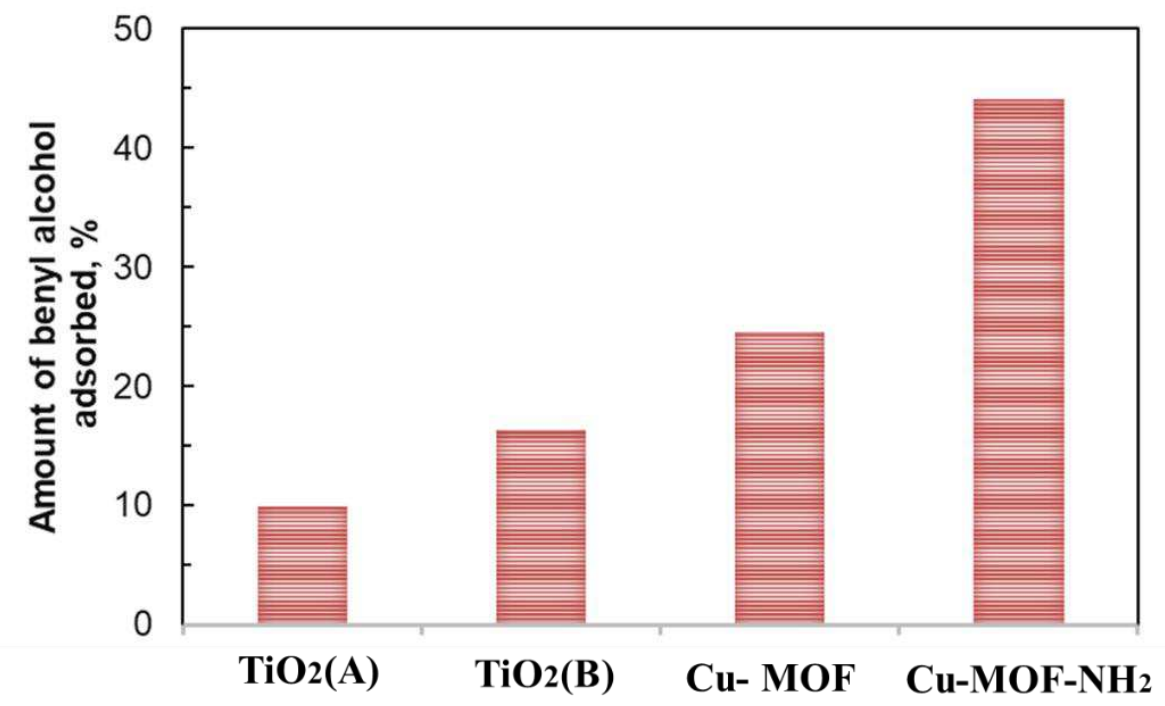

Figure 6: Adsorption of benzyl alcohol adsorbed from a benzyl alcohol solution ([Benzyl alcohol] = $500 \mathrm{mg} / \mathrm{L}$ solid content: $1 \mathrm{~g} / \mathrm{L}$ ) for prepared catalysts in the dark (equilibration time: $30 \mathrm{~min}$ ).

The data indicates that $\mathrm{TiO}_{2}(\mathrm{~B})$ (pure anatase) has a higher capacity for adsorption than $\mathrm{TiO}_{2}$ (A) (a mix of anatase and rutile), this is due to the following:

(a) The larger surface area and the smaller average size of the crystalline domains in $\mathrm{TiO}_{2}$ (B) would result in a higher adsorption capacity for benzyl alcohol on its surface. However, the increase is stronger than expected based on the increase in the surface area. The surface hydroxyl group density increases with increasing surface area [7], which may result in the enhanced adsorption of benzyl alcohol on $\mathrm{TiO}_{2}(\mathrm{~B})$ in comparison to $\mathrm{TiO}_{2}(\mathrm{~A})$.

(b) The adsorption capacity of rutile is lower than that of anatase for organic compounds (e.g., benzyl alcohol) [48], [49]. 
Similarly, both $\mathrm{Cu}-\mathrm{MOF}$ and $\mathrm{Cu}-\mathrm{MOF}-\mathrm{NH}_{2}$ displayed a high capacity for adsorption owing to the porous-like heterostructure. However, the measured adsorption capacity of $\mathrm{Cu}-\mathrm{MOF}-\mathrm{NH}_{2}$ is about double the measured adsorption capacity of the unmodified $\mathrm{Cu}-\mathrm{MOF}$, despite the much smaller surface area and pore volume. The average pore diameter of $\mathrm{Cu}-\mathrm{MOF}$ is much smaller than the average pore diameter of $\mathrm{Cu}-\mathrm{MOF}-\mathrm{NH}_{2}$, which may induce diffusion limitations in the uptake measurement and equilibrium may not have been attained in a contacting time of 30 minutes.

The photooxidation of benzyl alcohol was monitored on currently prepared catalysts $\mathrm{TiO}_{2}(\mathrm{~A}), \mathrm{TiO}_{2}(\mathrm{~B}), \mathrm{Cu}-\mathrm{MOF}$, and $\mathrm{Cu}-\mathrm{MOF}-\mathrm{NH}_{2}$ as a function of time under irradiation with visible light emitted from the mercury lamp at room temperature in the presence of $\mathrm{O}_{2}$. This reaction was completed within $240 \mathrm{~min}$ in acetonitrile solution as a solvent. Figure 7 shows that all catalysts exhibit good catalytic performance in the photooxidation of benzyl alcohol with benzaldehyde and benzyl benzoate as the main products. The only observed products were benzaldehyde and benzyl benzoate (see Fig. 8 and Fig. 9)

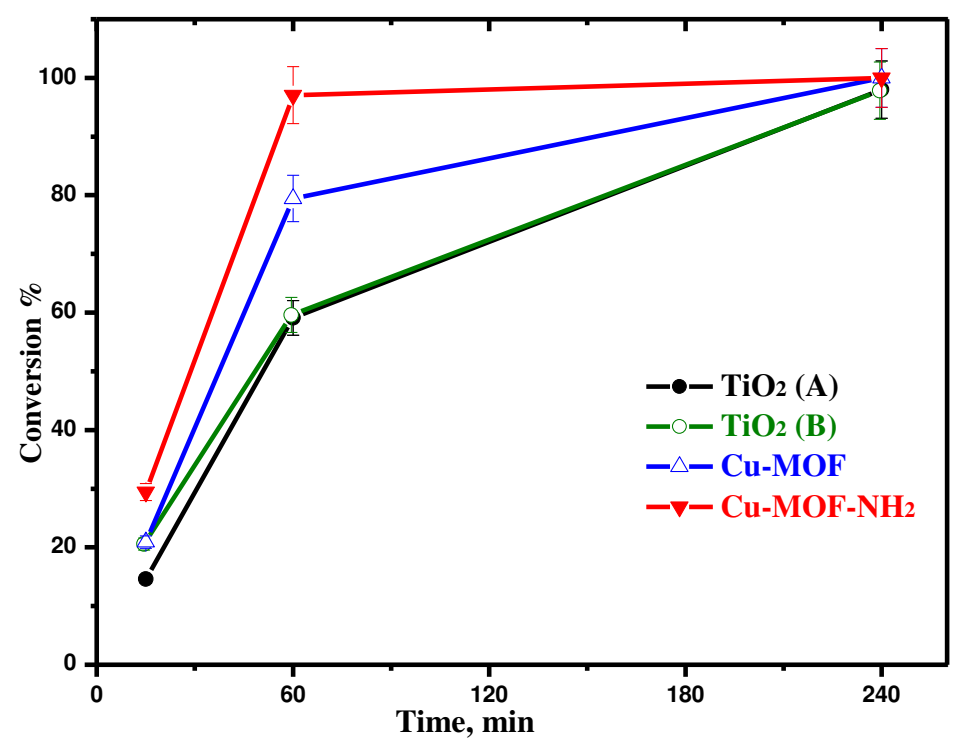

Figure 7: Photooxidations of benzyl alcohol were performed on currently prepared catalysts $\mathrm{TiO}_{2}(\mathrm{~A})$, $\mathrm{TiO}_{2}(\mathrm{~B}), \mathrm{Cu}-\mathrm{MOF}$, and $\mathrm{NH}_{2}-\mathrm{Cu}-\mathrm{MOF}$ as a function of time under irradiation with visible light emitted from the mercury lamp at room temperature in the presence of $\mathrm{O}_{2}$. $(150 \mathrm{ml}$ of $500 \mathrm{mg} / \mathrm{L} \mathrm{Benzyl}$ alcohol and $1 \mathrm{~g} / \mathrm{L}$ of catalyst; bubbling air, $25 \mathrm{~mL} / \mathrm{min}$ ).

Extrapolating the conversion time graph indicates that the intercept is less than zero. Hence, the conversion as a function of time is increasing strongly in the first 15 minutes of reaction ( $\mathrm{t}<15$ minutes), which is characteristic for an autocatalytic reaction. This may be caused by the conversion of the product, benzoic acid, with the the reactant, 
benzyl alcohol, enhancing the rate of benzyl alcohol conversion via the creation of benzyl benzoate [50]. It should be noted that we did not observe the formation of benzoic acid from the photocatalytic oxidation (as it was at a low concentration (near or under GC detection limit) [51].

Increasing the reaction time (up to $240 \mathrm{~min}$ ) increases the benzyl alcohol conversion with a modest increase in the selectivity for benzyl aldehyde and accordingly a modest decrease in the selectivity for benzyl benzoate. This is not accompanied by an increase in the formation of benzoic acid, and hence the decrease in the selectivity towards benzyl benzoate is not due to the reverse esterification of benzoic acid with benzyl alcohol. Thus, the decrease in benzyl benzoate selectivity is attributed to an increase in the rate of formation of benzaldehyde at the increased conversion of benzyl alcohol as the reaction period increases.

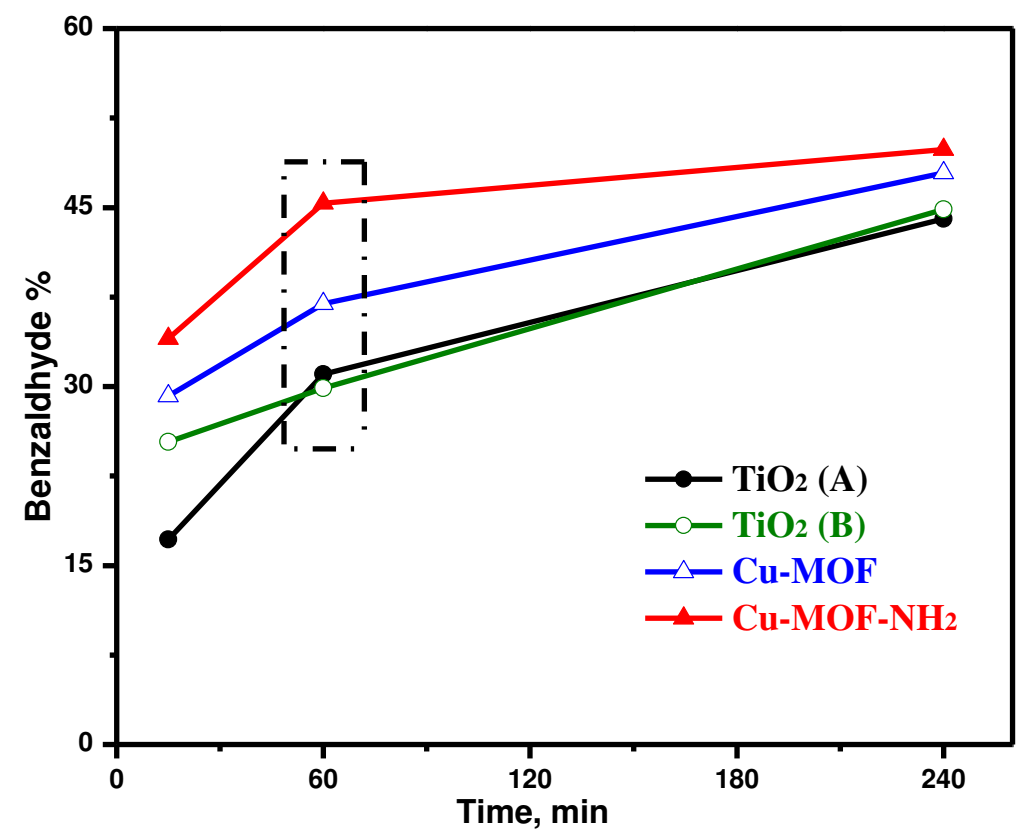

Figure 8: Selectivity of benzaldehyde over currently prepared catalysts as a function of reaction time (150 ml of $500 \mathrm{mg} / \mathrm{L}$ benzyl alcohol and $1 \mathrm{~g} / \mathrm{L}$ of catalyst; bubbling air, $25 \mathrm{~mL} / \mathrm{min}$; Hg-lamp). 


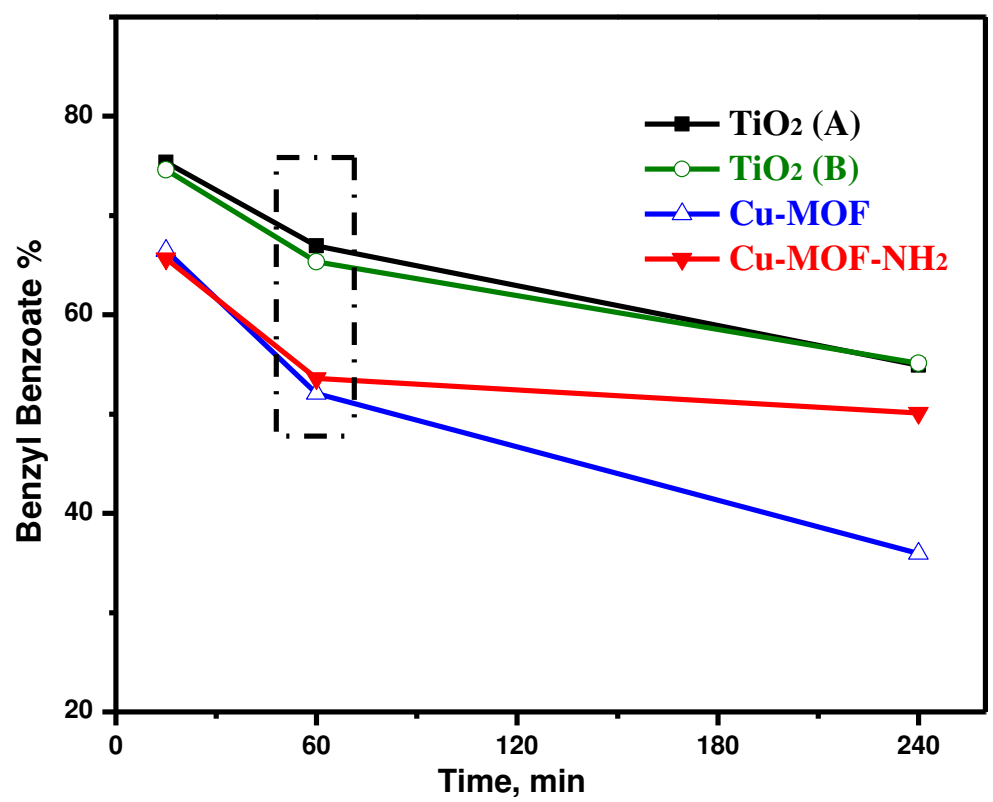

Figure 9: Selectivity of benzyl benzoate over currently prepared catalysts as a function of reaction time (150 $\mathrm{ml}$ of $500 \mathrm{mg} / \mathrm{L}$ benzyl alcohol and $1 \mathrm{~g} / \mathrm{L}$ of catalyst; bubbling air, $25 \mathrm{~mL} / \mathrm{min}$; Hg-lamp).

The performance difference between the catalysts $\mathrm{TiO}_{2}(\mathrm{~A})$ and $\mathrm{TiO}_{2}$ (B) for the photocatalytic oxidation of benzyl alcohol in terms of activity and selectivity is negligible (see Figs. 7-9), despite the difference in the phase composition and the available surface area. The obtained activity and selectivity may be attributed to:

(1) The generation of non-selective ${ }^{\cdot} \mathrm{OH}$ radicals can be avoided in acetonitrile $\left(\mathrm{CH}_{3} \mathrm{CN}\right)$ as a solvent [52], and therefore the complete oxidation to $\mathrm{CO}_{2}$ can be minimized [53].

(2) Superoxide anion radicals of ${ }^{\cdot} \mathrm{O}^{2-}$ are generated from $\mathrm{O}_{2}$ according to the valence band potential of the catalysts. Basic ${ }^{\circ} \mathrm{O}^{2-}$ removes protons from benzyl alcohol to form alkoxide anions. Alkoxide radicals are produced from alkoxide anions when they come into contact with a photogenerated hole. Then, the alkoxide reacts with another ${ }^{\circ} \mathrm{O}^{2-}$ and hole, releasing another proton from the hydroxymethyl moiety and forming a carbon radical [54].

(3) Carbon radicals may also be formed during the photocatalytic reaction when benzyl alcohol molecules react with photogenerated holes, followed by reducing Ti (IV) to Ti (III) via electron transfer.

(4) A swift reaction of carbon radicals and chemisorbed oxygen atoms cause fast oxidation of benzaldehyde to benzoic acid and subsequent esterification to benzyl benzoate (the solvent plays a critical role as a moderately polar solvent 
and basic medium for driving the reaction toward the production of benzyl benzoate [11]).

The performance of $\mathrm{Cu}-\mathrm{MOF}$ and $\mathrm{Cu}-\mathrm{MOF}-\mathrm{NH}_{2}$ in the photooxidation of benzyl alcohol yielding benzyl aldehyde and benzyl benzoate is quite different (especially at the beginning of the reaction up to $60 \mathrm{~min}$ ). $\mathrm{Cu}-\mathrm{MOF}-\mathrm{NH}_{2}$ exhibits a higher catalytic activity and selectivity towards benzaldehyde formation.

The reaction kinetics of the selective photocatalytic oxidation of benzyl alcohol to benzaldehyde are investigated to understand the intrinsic activities of the catalysts. The conversion in the first 60 minutes of the reaction is seemingly independent of the conversion, and hence the initial rates were determined from the slope of the conversion-time graphs.

$$
-r_{\text {benzyl alcohol }}=C_{0} \cdot\left(\frac{d X}{d t}\right)_{\text {initial }}=-\left(\frac{d C}{d t}\right)_{\text {initial }}
$$

With $\mathrm{C}_{0}$, the initial concentration of benzyl alcohol and $\mathrm{X}$ the conversion of benzyl alcohol. The initial activity of the titania catalysts $\left(\mathrm{TiO}_{2}(\mathrm{~A})\right.$ and $\left.\mathrm{TiO}_{2}(\mathrm{~B})\right)$ are virtually the same (initial rate of 4.6 and $4.7 \mathrm{mmol} / \mathrm{g} / \mathrm{min}$, respectively). The catalysts $\mathrm{Cu}-\mathrm{MOF}$ and $\mathrm{Cu}-\mathrm{MOF}-\mathrm{NH}_{2}$ have a higher initial rate of reaction of 6.1 and $9.1 \mathrm{mmol} / \mathrm{g} / \mathrm{min}$. The different reactivity of the MOFs compared to titania may be attributed to the change in the catalytic active surface area and the difference in the band gap between the materials.

The band gap for titania is ca. 3.0-3.2 eV. Figure 10 shows the UV-Vis diffuse reflectance spectra of $\mathrm{Cu}-\mathrm{MOF}$ and $\mathrm{Cu}-\mathrm{MOF}-\mathrm{NH}_{2}$. The optical absorption edge for $\mathrm{Cu}-$ MOF is estimated at $320 \mathrm{~nm}$, and the calculated optical band gap of $\mathrm{Cu}-\mathrm{MOF}$ is $3.9 \mathrm{eV}$ based on the relationship $\mathrm{E}_{\mathrm{g}}=1240 / \lambda[35,58]$. This implies that $\mathrm{Cu}-\mathrm{MOF}$ will absorb a smaller fraction of the light emitted by the mercury lamp compared to titania catalysts. This would imply a low reactivity of this material in the photocatalytic conversion of benzyl alcohol, but the much higher surface area countere this. 

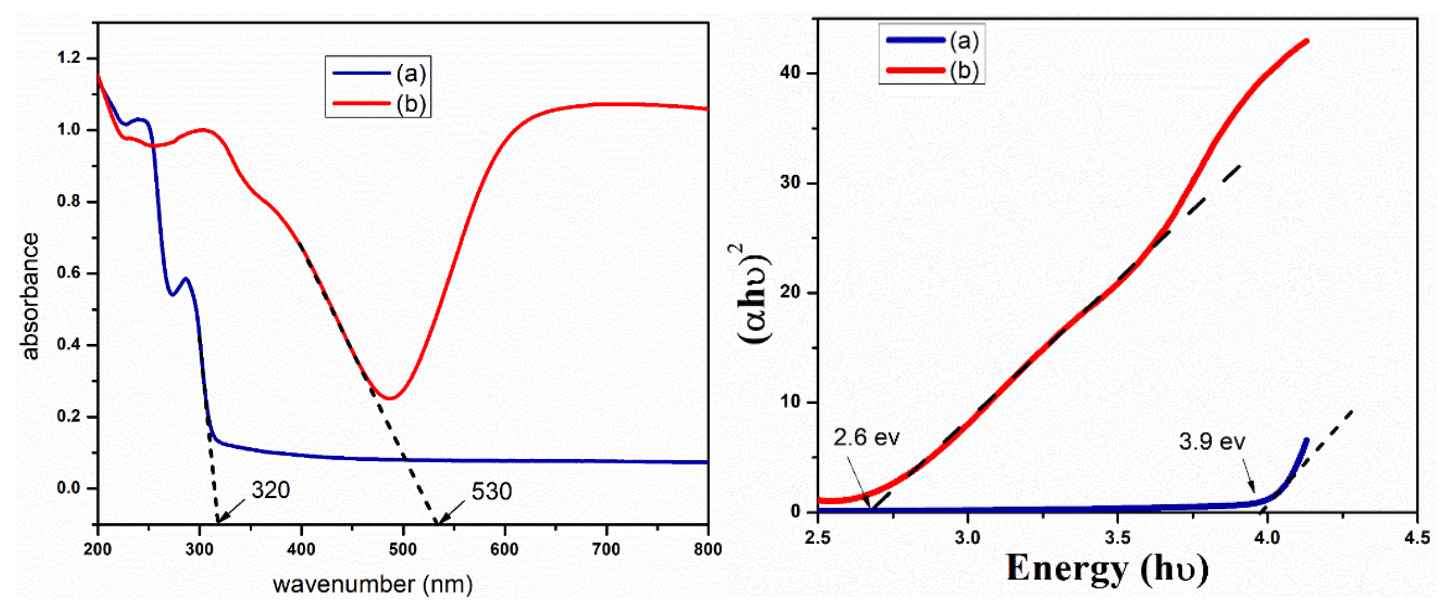

Figure (10): UV-Vis diffuse reflectance spectra (left) and ( $\alpha$ hv $)^{2}$ vs. hv curves (right) of (a) Cu-MOF and (b) $\mathrm{Cu}-\mathrm{MOF}-\mathrm{NH}_{2}$.

A linker decoration such as an amine modifies the bandgap, which moves the absorption energy from the ultraviolet to the visible region. The amino decoration acts as an auxochromic and bathochromic group in the aromatic ring, leading to the absorption wavelength shift of $\mathrm{Cu}$ - MOF [23]. Thus, introducing $\mathrm{NH}_{2}$-groups reduces the bandgap from 3.9 to $2.6 \mathrm{eV}$, i.e., a redshift of absorption edges, this is following the predictions by Sliva et al. [56], who proved that inserting $\mathrm{NH}_{2}$ in UiO-66 decreased the band gap due to changes in the linker and the nonbonding oxygen near the metalloid cluster. The emitting radiation of the $125 \mathrm{~W}$ mercury lamp is in the range of 200 to 420 $\mathrm{nm}$ [57]. Therefore, only the light from 200 to $320 \mathrm{~nm}$ can be utilized for pristine $\mathrm{Cu}$ MOF. For the $\mathrm{Cu}-\mathrm{MOF}-\mathrm{NH}_{2}$ catalyst, the light from 200 to $420 \mathrm{~nm}$ can be utilized.

Furthermore, the maximum emission of the mercury lamp at $365 \mathrm{~nm}$, i.e., the light source's intensity, is the strongest at around $365 \mathrm{~nm}$, allowing for greater light utilization [28]. Therefore, the $\mathrm{Cu}-\mathrm{MOF}-\mathrm{NH}_{2}$ can absorb more light than the pristine $\mathrm{Cu}-\mathrm{MOF}$. As a result, the amine linker decoration improved light utilization capability, which resulted in increased activity for the photocatalytic conversion of benzyl alcohol despite the decrease in the surface area.

MOFs can be used as conventional semiconductor photocatalysts that can be excited when irradiated to create electrons and holes [32]. Decoration of MOF linker by $\mathrm{NH}_{2}$ can result in electron-rich clouds, which produce $\left(\mathrm{e}^{-}-\mathrm{h}^{+}\right)$pairs. It is suggested that accelerated electron migration and the high photocatalytic activity are obtained for $\mathrm{Cu}$ $\mathrm{MOF}-\mathrm{NH}_{2}$ due to an amine group adjacent to the organic linker. The electron is placed in the $\mathrm{Cu}$-oxo clusters, whereas the hole is located in the amino terephthalate unit, 
specifically, the amino group, which further enhances the electron transfer pathway in photo-excited $\mathrm{Cu}-\mathrm{MOF}-\mathrm{NH}_{2}$ [49,50]. Liu et al. [51] showed that that ZIF-8 MOF showed significantly higher photocatalytic activity in the photocatalytic reduction of $\mathrm{Cr}(\mathrm{IV})$ compared to titania due to the high $\mathrm{Cr}(\mathrm{VI})$ adsorption property of ZIF-8 and more efficient charge transfer compared to pristine $\mathrm{TiO}_{2}$ beads.

The MOF may absorb incident photons under visible light irradiation. The photogenerated carriers then migrate to the MOF surface and take part in the redox reaction. The adsorbed oxygen is reduced to superoxide radicals $\left({ }^{\circ} \mathrm{O}_{2}^{-}\right)$by photogenerated electrons, and the photogenerated holes $\left(\mathrm{h}^{+}\right)$on the MOF surface induce benzyl alcohol to release protons directly under the help of $\left({ }^{\circ} \mathrm{O}_{2}^{-}\right)$which results in benzaldehyde. The absence of benzoic acid in the GC analysis indicates that, once benzoic acid is formed (reaction (4)), it reacts directly with benzyl alcohol, which is existing in a much higher concentration, forming benzyl benzoate (reaction (5)).

$$
\begin{aligned}
& \text { MOFs }+ \text { hv } \rightarrow \text { MOFS }\left(h^{+}+e^{-}\right) \\
& e^{-}+\mathrm{O}_{2} \rightarrow \mathrm{O}_{2}^{-} \\
& \mathrm{C}_{6} \mathrm{H}_{5} \mathrm{CH}_{2} \mathrm{OH}+\frac{1}{2} \mathrm{O}_{2}^{-} \rightarrow \mathrm{C}_{6} \mathrm{H}_{5} \mathrm{CHO}+\mathrm{H}_{2} \mathrm{O} \\
& \mathrm{C}_{6} \mathrm{H}_{5} \mathrm{CHO}+\frac{1}{2} \mathrm{O}_{2}^{-} \rightarrow \mathrm{C}_{6} \mathrm{H}_{5} \mathrm{COOH}+\mathrm{H}_{2} \mathrm{O} \\
& \mathrm{C}_{6} \mathrm{H}_{5} \mathrm{COOH}+\mathrm{C}_{6} \mathrm{H}_{5} \mathrm{CH}_{2} \mathrm{OH} \rightarrow \mathrm{C}_{6} \mathrm{H}_{5} \mathrm{COOCH}_{2} \mathrm{COH}_{6} \mathrm{H}_{5}+\mathrm{H}_{2} \mathrm{O}
\end{aligned}
$$

\section{Conclusion}

Photocatalytic oxidation of benzyl alcohol using titania-based materials, $\mathrm{Cu}-\mathrm{MOF}$, and $\mathrm{Cu}-\mathrm{MOF}-\mathrm{NH}_{2}$, with a mercury lamp in aerated acetonitrile, has been carried out used for selective oxidation to the corresponding carbonyl compounds. The performance of different titania was virtually identical despite differences in the phase composition and surface area. The $\mathrm{Cu}-\mathrm{MOF}$ was more active than titania, although the effectiveness of light adsorption from the mercury lamp on these materials is less than on titania; the increased activity is attributed to the much higher surface area of this material which 
may compensate for the reduced light absorption. Modification of $\mathrm{Cu}-\mathrm{MOF}$ with ethylene diamine allows for absorption of light at much higher wavelengths, thus increasing light absorption efficiency. This resulted in an increased activity despite a strong reduction in the surface area. These results made MOFs and functioned MOFs to be promising materials for exceptional chemical preparation.

\section{Compliance with Ethical Standards:}

The authors declare that they have no conflict of interest.

\section{Reference:}

[1] N. C. Jeong, O. K. Farha, and J. T. Hupp, "A convenient route to high area, nanoparticulate $\mathrm{TiO} 2$ photoelectrodes suitable for high-efficiency energy conversion in dye-sensitized solar cells," Langmuir, vol. 27, no. 5, pp. 19961999, 2011.

[2] N. Alenzi et al., "Photoelectrochemical hydrogen production from water/methanol decomposition using $\mathrm{Ag} / \mathrm{TiO} 2$ nanocomposite thin films," Int. J. Hydrogen Energy, vol. 35, no. 21, pp. 11768-11775, 2010, doi: https://doi.org/10.1016/j.ijhydene.2010.08.020.

[3] Q. Li et al., "Highly Efficient Visible-Light-Driven Photocatalytic Hydrogen Production of CdS-Cluster-Decorated Graphene Nanosheets," J. Am. Chem. Soc., vol. 133, no. 28, pp. 10878-10884, Jul. 2011, doi: 10.1021/ja2025454.

[4] J. Li, J. Liu, S. Liao, and R. Yan, "Hydrogen-rich gas production by air e steam gasification of rice husk using supported nano-NiO / g -Al 2 O 3 catalyst," Int. J. Hydrogen Energy, vol. 35, no. 14, pp. 7399-7404, 2010, doi: 10.1016/j.ijhydene.2010.04.108.

[5] G. Palmisano et al., "Advances in selective conversions by heterogeneous photocatalysis," Chem. Commun., vol. 46, no. 38, pp. 7074-7089, 2010, doi: 10.1039/C0CC02087G.

[6] V. Augugliaro et al., "Photocatalytic oxidation of aromatic alcohols to aldehydes in aqueous suspension of home-prepared titanium dioxide: 1 . Selectivity enhancement by aliphatic alcohols," Appl. Catal. A Gen., vol. 349, no. 1, pp. 182-188, 2008, doi: https://doi.org/10.1016/j.apcata.2008.07.032.

[7] C. Li, G. Xu, B. Zhang, and J. Ru, "Applied Catalysis B : Environmental High 
selectivity in visible-light-driven partial photocatalytic oxidation of benzyl alcohol into benzaldehyde over single-crystalline rutile TiO 2 nanorods," "Applied Catal. B, Environ., vol. 115-116, pp. 201-208, 2012, doi: 10.1016/j.apcatb.2011.12.003.

[8] E. I. García et al., "Selective oxidation of aromatic alcohols in the presence of melamine , cyanuric and barbituric acids," Res. Chem. Intermed., vol. 47, no. 1, pp. 131-156, 2021, doi: 10.1007/s11164-020-04330-5.

[9] C. Ling, X. Ye, J. Zhang, J. Zhang, and S. Zhang, "Solvothermal synthesis of CdIn 2 S 4 photocatalyst for selective photosynthesis of organic aromatic compounds under visible light," Sci. Rep., no. December, pp. 1-16, 2016, doi: 10.1038/s41598-017-00055-5.

[10] G. Nagy et al., "Selective aerobic oxidation of benzyl alcohol on alumina supported Au-Ru and Au-Ir catalysts," Mol. Catal., vol. 492, no. February, p. 110917, 2020, doi: 10.1016/j.mcat.2020.110917.

[11] E. Skupien et al., "Inhibition of a Gold-Based Catalyst in Benzyl Alcohol Oxidation: Understanding and Remediation,” pp. 89-115, 2014, doi: $10.3390 /$ catal4020089.

[12] Y. Shiraishi and T. Hirai, "Selective organic transformations on titanium oxidebased photocatalysts," J. Photochem. Photobiol. C Photochem. Rev., vol. 9, no. 4, pp. 157-170, 2008, doi: https://doi.org/10.1016/j.jphotochemrev.2008.05.001.

[13] G. Marcì, E. I. García-López, and L. Palmisano, "20 - Fine chemistry by TiO2 heterogeneous photocatalysis," in Metal Oxides, F. Parrino and L. B. T.-T. D. $\left(\mathrm{Tio}_{2}\right)$ and I. A. Palmisano, Eds. Elsevier, 2021, pp. 609-635.

[14] H. Song et al., "Template-free synthesis of hollow TiO2 nanospheres supported Pt for selective photocatalytic oxidation of benzyl alcohol to benzaldehyde," Green Energy Environ., vol. 4, no. 3, pp. 278-286, 2019, doi: https://doi.org/10.1016/j.gee.2018.09.001.

[15] L. Özcan et al., “Applied Catalysis B : Environmental Photoelectrocatalytic selective oxidation of 4-methoxybenzyl alcohol in water by TiO 2 supported on titanium anodes," "Applied Catal. B, Environ., vol. 132-133, pp. 535-542, 2013, doi: 10.1016/j.apcatb.2012.12.030.

[16] H. Wei, J. Li, J. Yu, J. Zheng, H. Su, and X. Wang, "Gold Nanoparticles Supported on Metal Oxides as Catalysts for the Direct Oxidative Esterification 
of Alcohols under Mild Conditions," Inorganica Chim. Acta, 2014, doi: 10.1016/j.ica.2014.11.024.

[17] S. Yurdakal, C. Garlisi, L. Özcan, and M. Bellardita, “(Photo)catalyst Characterization Techniques," 2019, pp. 87-152.

[18] J. Tian, Z. Zhao, A. Kumar, R. I. Boughton, and H. Liu, "Recent progress in design, synthesis, and applications of one-dimensional $\mathrm{TiO} 2$ nanostructured surface heterostructures: a review," Chem. Soc. Rev., vol. 43, no. 20, pp. 69206937, 2014, doi: 10.1039/C4CS00180J.

[19] D. A. H. Hanaor and C. C. Sorrell, "Review of the anatase to rutile phase transformation," J. Mater. Sci., vol. 46, no. 4, pp. 855-874, 2011, doi: 10.1007/s10853-010-5113-0.

[20] A. Kafizas, A. Kafizas, and I. P. Parkin, "Combinatorial atmospheric pressure chemical vapor deposition (cAPCVD): a route to functional property optimization," J. Am. Chem. Soc., vol. 133, no. 50, pp. 20458-20467, 2011, doi: $10.1021 / j a 208633 g$.

[21] J. M. Coronado, A. J. Maira, J. C. Conesa, K. L. Yeung, V. Augugliaro, and J. Soria, "EPR Study of the Surface Characteristics of Nanostructured TiO2 under UV Irradiation,” Langmuir, vol. 17, no. 17, pp. 5368-5374, Aug. 2001, doi: 10.1021/la010153f.

[22] J. Yao and H. Wang, "Zeolitic imidazolate framework composite membranes and thin films: synthesis and applications," Chem. Soc. Rev., vol. 43, no. 13, pp. 4470-4493, 2014, doi: 10.1039/C3CS60480B.

[23] J. Qiu, Y. Feng, X. Zhang, M. Jia, and J. Yao, “Acid-promoted synthesis of UiO-66 for highly selective adsorption of anionic dyes: Adsorption performance and mechanisms.," J. Colloid Interface Sci., vol. 499, pp. 151158, Aug. 2017, doi: 10.1016/j.jcis.2017.03.101.

[24] J. Qiu, X. Zhang, Y. Feng, X. Zhang, H. Wang, and J. Yao, "Modified metalorganic frameworks as photocatalysts," "Applied Catal. B, Environ., no. March, 2018, doi: 10.1016/j.apcatb.2018.03.039.

[25] A. W. Stubbs et al., "Selective Catalytic Olefin Epoxidation with MnIIExchanged MOF-5," ACS Catal., vol. 8, no. 1, pp. 596-601, Jan. 2018, doi: 10.1021/acscatal.7b02946.

[26] P. Horcajada et al., "Porous metal-organic-framework nanoscale carriers as a potential platform for drug delivery and imaging.," Nat. Mater., vol. 9, no. 2, 
pp. 172-178, Feb. 2010, doi: 10.1038/nmat2608.

[27] Z.-Z. Lu, R. Zhang, Y.-Z. Li, Z.-J. Guo, and H.-G. Zheng, "Solvatochromic behavior of a nanotubular metal-organic framework for sensing small molecules.," J. Am. Chem. Soc., vol. 133, no. 12, pp. 4172-4174, Mar. 2011, doi: $10.1021 /$ ja109437d.

[28] Y. Shi, A. Yang, C. Cao, and B. Zhao, “Applications of MOFs : Recent advances in photocatalytic hydrogen production from water," Coord. Chem. Rev., vol. 390, pp. 50-75, 2019, doi: 10.1016/j.ccr.2019.03.012.

[29] D. Wang and Z. Li, "Coupling MOF-based photocatalysis with Pd catalysis over Pd @ MIL-100 ( Fe ) for efficient N-alkylation of amines with alcohols under visible light," vol. 342, pp. 151-157, 2016, doi: 10.1016/j.jcat.2016.07.021.

[30] D. Wang and Z. Li, "Bi-functional NH2-MIL-101(Fe) for one-pot tandem photo-oxidation/Knoevenagel condensation between aromatic alcohols and active methylene compounds," Catal. Sci. Technol., vol. 5, no. 3, pp. 16231628, 2015, doi: 10.1039/C4CY01464B.

[31] L. Chen et al., "Heterogeneous photocatalysis for selective oxidation of alcohols and hydrocarbons," Appl. Catal. B Environ., vol. 242, pp. 379-388, 2019, doi: https://doi.org/10.1016/j.apcatb.2018.10.025.

[32] J. M. Hoover, B. L. Ryland, and S. S. Stahl, "Mechanism of Copper(I)/TEMPO-Catalyzed Aerobic Alcohol Oxidation,” no. I, 2013, doi: 10.1021/ja3117203.

[33] B. L. Ryland and S. S. Stahl, "Practical aerobic oxidations of alcohols and amines with homogeneous copper/TEMPO and related catalyst systems.," Angew. Chem. Int. Ed. Engl., vol. 53, no. 34, pp. 8824-8838, Aug. 2014, doi: 10.1002/anie.201403110.

[34] A. Taher, D. W. Kim, and I. Lee, "based copper catalysts for the base-free aerobic oxidation of various alcohols $\dagger, "$ no. Scheme 1, pp. 17806-17812, 2017, doi: 10.1039/c6ra28743c.

[35] Q. Hu et al., "Applied Surface Science In-situ preparation of NH 2 -MIL-125 ( $\mathrm{Ti}$ )/ $\mathrm{BiOCl}$ composite with accelerating charge carriers for boosting visible light photocatalytic activity," Appl. Surf. Sci., vol. 466, no. October 2018, pp. 525-534, 2019, doi: 10.1016/j.apsusc.2018.10.020.

[36] R. Zhong et al., "A solvent 'squeezing' strategy to graft ethylenediamine on 
Cu3(BTC)2 for highly efficient CO2/CO separation," Chem. Eng. Sci., vol. 184, pp. 85-92, 2018, doi: https://doi.org/10.1016/j.ces.2017.12.040.

[37] R. A. Spurr and H. Myers, "Quantitative Analysis of Anatase-Rutile Mixtures with an X-Ray Diffractometer,” Anal. Chem., vol. 29, no. 5, pp. 760-762, May 1957, doi: 10.1021/ac60125a006.

[38] L. Velardi, L. Scrimieri, A. Serra, D. Manno, and L. Calcagnile, "The synergistic role of $\mathrm{pH}$ and calcination temperature in sol-gel titanium dioxide powders," Appl. Phys. A, vol. 125, no. 10, p. 735, 2019, doi: 10.1007/s00339019-3038-2.

[39] S. M. Abdel-Azim, A. K. Aboul-Gheit, S. M. Ahmed, D. S. El-Desouki, and M. S. A. Abdel-Mottaleb, "Preparation and Application of Mesoporous Nanotitania Photocatalysts Using Different Templates and pH Media," Int. J. Photoenergy, vol. 2014, p. 687597, 2014, doi: 10.1155/2014/687597.

[40] S. Mahshid, M. Askari, and M. S. Ghamsari, "Synthesis of TiO 2 nanoparticles by hydrolysis and peptization of titanium isopropoxide solution," vol. 189, pp. 296-300, 2007, doi: 10.1016/j.jmatprotec.2007.01.040.

[41] Y. Wang, "Electrochemical determination of 2, 4, 6-trinitrophenol using a hybrid film composed of a copper-based metal organic framework and electroreduced graphene oxide," pp. 1-9, 2018.

[42] M. J. Cliffe et al., "Correlated defect nanoregions in a metal-organic framework.," Nat. Commun., vol. 5, p. 4176, Jun. 2014, doi: 10.1038/ncomms5176.

[43] G. Wang, L. Xu, J. Zhang, T. Yin, and D. Han, "Enhanced Photocatalytic Activity of TiO 2 Powders ( P25 ) via Calcination Treatment," vol. 2012, 2012, doi: $10.1155 / 2012 / 265760$.

[44] E. R. Morales et al., "Physical properties of the CNT:TiO2 thin films prepared by sol-gel dip coating," Sol. Energy, vol. 86, no. 4, pp. 1037-1044, 2012, doi: 10.1016/j.solener.2011.06.027.

[45] H. M. Abd El Salam, S. A. Younis, H. R. Ali, and T. Zaki, "Statistical modeling and optimization of phenol adsorption from water by modified Cu3(BTC)2: Kinetic, isotherm, and thermodynamic analysis," Microporous Mesoporous Mater., vol. 241, pp. 210-217, 2017, doi: https://doi.org/10.1016/j.micromeso.2016.12.010.

[46] N. M. El-Ashgar, I. M. El-Nahhal, M. M. Chehimi, F. Babonneau, and J. 
Livage, "Preparation of ethylenediaminetriacetic acid silica-gel immobilised ligand system and its application for trace metal analysis in aqueous samples," Int. J. Environ. Anal. Chem., vol. 89, no. 14, pp. 1057-1069, Dec. 2009, doi: 10.1080/03067310902717278.

[47] M. Wickenheisser, F. Jeremias, S. K. Henninger, and C. Janiak, "Grafting of hydrophilic ethylene glycols or ethylenediamine on coordinatively unsaturated metal sites in MIL-100(Cr) for improved water adsorption characteristics," Inorganica Chim. Acta, vol. 407, pp. 145-152, 2013, doi: https://doi.org/10.1016/j.ica.2013.07.024.

[48] A. G. Thomas and K. L. Syres, "Adsorption of organic molecules on rutile TiO2 and anatase TiO2 single crystal surfaces," Chem. Soc. Rev., vol. 41, no. 11, pp. 4207-4217, 2012, doi: 10.1039/C2CS35057B.

[49] A. Holm, M. Hamandi, F. Simonet, B. Jouguet, F. Dappozze, and C. Guillard, "Applied Catalysis B : Environmental Impact of rutile and anatase phase on the photocatalytic decomposition of lactic acid," Appl. Catal. B Environ., vol. 253, no. September 2018, pp. 96-104, 2019, doi: 10.1016/j.apcatb.2019.04.042.

[50] V. R. Choudhary, R. Jha, and P. Jana, "Solvent-free selective oxidation of benzyl alcohol by molecular oxygen over uranium oxide supported nano-gold catalyst for the production of chlorine- free benzaldehyde," pp. 267-272, 2007, doi: 10.1039/b608304h.

[51] G. Nagy et al., "Selective aerobic oxidation of benzyl alcohol on alumina supported Au-Ru and Au-Ir catalysts," Mol. Catal., vol. 492, no. May, p. 110917, 2020, doi: 10.1016/j.mcat.2020.110917.

[52] D. O. Scanlon et al., "Band alignment of rutile and anatase TiO 2," vol. 12, no. July, pp. 10-13, 2013, doi: 10.1038/nmat3697.

[53] S. Higashimoto, N. Kitao, N. Yoshida, T. Sakura, and M. Azuma, "Selective photocatalytic oxidation of benzyl alcohol and its derivatives into corresponding aldehydes by molecular oxygen on titanium dioxide under visible light irradiation," J. Catal., vol. 266, no. 2, pp. 279-285, 2009, doi: 10.1016/j.jcat.2009.06.018.

[54] S. K. Pahari and R. Doong, "Few-Layered Phosphorene - Graphitic Carbon Nitride Nanoheterostructure as a Metal-Free Photocatalyst for Aerobic Oxidation of Benzyl Alcohol and Toluene," 2020, doi: 10.1021/acssuschemeng.0c04078. 
[55] P. Makuła, M. Pacia, and W. Macyk, "How To Correctly Determine the Band Gap Energy of Modified Semiconductor Photocatalysts Based on UV-Vis Spectra,” J. Phys. Chem. Lett., vol. 9, no. 23, pp. 6814-6817, Dec. 2018, doi: 10.1021/acs.jpclett.8b02892.

[56] C. G. Silva, I. Luz, F. X. Llabrøs, and A. Corma, "Water Stable Zr Benzenedicarboxylate Metal - Organic Frameworks as Photocatalysts for Hydrogen Generation,” pp. 11133-11138, 2010, doi:

10.1002/chem.200903526.

[57] Y. Shi, A.-F. Yang, C.-S. Cao, and B. Zhao, “Applications of MOFs: Recent advances in photocatalytic hydrogen production from water," Coord. Chem. Rev., vol. 390, pp. 50-75, 2019, doi: https://doi.org/10.1016/j.ccr.2019.03.012.

[58] J. G. Santaclara et al., "Organic Linker Defines the Excited-State Decay of Photocatalytic MIL-125(Ti)-Type Materials," ChemSusChem, vol. 9, no. 4, pp. 388-395, Feb. 2016, doi: https://doi.org/10.1002/cssc.201501353.

[59] X. Liu et al., "Applied Catalysis B : Environmental A sandwich-like heterostructure of TiO 2 nanosheets with MIL-100 ( Fe ): A platform for efficient visible-light-driven photocatalysis," "Applied Catal. B, Environ., vol. 209, pp. 506-513, 2017, doi: 10.1016/j.apcatb.2017.02.073. 


\section{Supplementary Files}

This is a list of supplementary files associated with this preprint. Click to download.

- supplementrydatafinal.docx 